\title{
Influence of age and hypertension on functional performance of stroke patients in rehabilitation
}

\begin{abstract}
Background: The effect of age and hypertension on the functional performance of stroke patients with inpatient rehabilitation has not been studied in the past.

Objective: To examine whether advanced age and hypertension influence the functional gains of stroke patients undergoing rehabilitation.

Methods: The charts of two hundred and seventy- two patients with thromboembolic strokes from an impatient rehabilitation unit divided into five age groups $(<49,50$ to 59,60 to 69,70 to 79 and $>80$ years) were reviewed. The patients' functional progress was measured by the Functional Independence Measure (FIM) at admission (A-FIM) and at discharge (D-FIM). The difference of D-FIM from A-FIM is the gain in FIM. This gain in FIM as a fraction of the Length of Stay (LOS) is the Efficiency Ratio (ER). The differences among the averages of the five age groups of the A-FIM, D-FIM, LOS and ER for the male-female and hypertensive-non-hypertensive groups were statistically analyzed separately through the Analysis of Variance (ANOVA), the F-ratios and the Student's t-tests.
\end{abstract}

Results: Patients younger than 60 years of age had statistically significant $(\mathrm{p}<0.00004)$ functional progress (ER) compared to patients older than 60. Similarly, nonhypertensives 60 and younger had higher functional gains than hypertensive patients $(p<0.05)$ while there was no significant difference among the patients over age 60 with or without hypertension.

Conclusion: Younger non-hypertensive patients seem to show better progress with inpatient rehabilitation.

Keywords: stroke, hypertension, rehabilitation
Volume 4 Issue 4 - 2019

\section{Kanakadurga R Poduri,' Sara Salim,' Sotto Ramon $^{2}$}

'Department of Physical and Rehabilitation Medicine, University of Rochester Medical Center, USA

${ }^{2}$ Interventional Pain, Physical Medicine and Rehabilitation, USA

\begin{abstract}
Correspondence: Kanakadurga R Poduri, Department of Physical and Medicine and Rehabilitation University of Rochester Medical Center, 60I Elmwood Avenue, Box 664, Rochester, NY I 4642, Tel (585) 275-6344, (585) 208-0629, Email KR_Poduri@urmc.rochester.edu
\end{abstract}

Received: May 29, 2019 | Published: July 15, 2019

\section{Introduction}

Stroke is one of the leading causes of serious and long-term disability worldwide. ${ }^{1}$ Many patients consider having a stroke to be worse than death because of the impaired functions. ${ }^{2}$ As of 2008, the cost of stroke and its sequelae in the USA alone was an estimated 65.5 billion dollars. ${ }^{3}$ Besides the cost involved in treatment of stroke, restoration of function, maximization of independence and improvement of quality of life have been the primary concerns for rehabilitation physicians and researchers.

The outcome for stroke recovery is recognized to be strongly related to the age of the patient. In general, younger individuals are expected to recover strength and function from rehabilitation much sooner than older adults. However, the differences among the age groups for the functional recovery from stroke rehabilitation are not firmly established.

As early as 1957 , Rankin noted that mortality rates after cerebral vascular events were similar for any age group over 40 years. He also noted that there was a slight negative association between age and functional status upon discharge. ${ }^{4}$ Lehmann et al. supported the prior studies which indicated that age had a negative association with discharge function and lack of association with improvement of function. ${ }^{5,6}$ In the 1980s, a number of studies suggested that age was less of a determinant for functional recovery than expected. In addition, systematic functional assessment tools such as the Barthel index were adopted to provide validity and reliability to the observed data. $^{7-9}$

In the 1990's Ferrucci et al. ${ }^{10}$ and Nakayama et al. ${ }^{11}$ suggested that while the rates of improvement in stroke patients of differing ages were similar, the changes in younger populations can be expected to represent actual neural improvements, but improvement in older populations may depend more on the employment of compensatory strategies. ${ }^{10,11}$ It has also been noted that co-morbid conditions may account for any differences in functional recovery for individuals older than 75 years of age and that well-organized management plans are associated with the best outcomes for the elderly. ${ }^{12-14}$

More recently, Black-Schaffer and Winston ${ }^{15}$ observed a relationship between increasing age and poorer outcome for patients with admission FIM score $<40$, a variable relationship if it is $40-80$, and no relationship if it is $>80 .{ }^{15}$ Luk found that age was not a predictor of functional outcome, but admission functional status, employment, and independence prior to stroke were more commonly associated with good outcomes following stroke rehabilitation. ${ }^{16}$

As can be seen, the above studies refer to the effect of age and other factors on stroke recovery. Nazzal et al. studied the effect of risk factors on the functional outcome after stroke rehabilitation using Barthel Index and found that those with one or two comorbidities had the highest score of improvement after rehabilitation while the group of patients with more than two co-morbidities did 
not show any improvement. ${ }^{18}$ This retrospective study concluded that younger patients showed a tendency for better improvement. It included hypertension as one of the comorbid conditions but the effect of hypertension itself on functional improvement was not studied. Another similar study showed that diabetes did not seem to significantly impact short-term acute rehabilitation outcomes after stroke. $^{19}$

Salehi et al. ${ }^{20}$ evaluated factors affecting quality of life post stroke using the Stroke Impact Scale-16. They noted that increased age and hypertension were both factors correlating with poorer quality of life post stroke. Cao et al. ${ }^{21}$ published a retrospective study examining hypertensive patients who had an ischemic stroke. They found that hypertensive patients who were on antihypertensive treatment prior to their stroke had better functional outcomes (modified Rankin Scale) post stroke compared to those who were not on treatment. Tanovic et al. ${ }^{22}$ evaluated the influence of hypertension on stroke patients, and found that those with hypertension had significantly poorer outcomes on the Barthel Index than those without.

Since hypertension is the major cause of strokes, in our study we have evaluated the effect of both age and hypertension on stroke patients using the Functional Independence Measure (FIM), a widely accepted functional outcome measure. We have examined the functional performance for both the hypertensive and nonhypertensive patients separately and for the male and female patients with or without hypertension.

\section{Design and methods}

This is a retrospective observational study from the acute inpatient rehabilitation unit at the University of Rochester Medical Center in Rochester, New York in the United States of America. The data were collected from medical records of stroke patients who underwent inpatient rehabilitation during the years 2004-2007. Two hundred and seventy- two patients with thrombo- embolic strokes were included. The patients were divided into five age groups: less than 49 years, 50-59 years, $60-69$ years, $70-79$ years and greater than 80 years. They were further classified into the hypertensive and non-hypertensive groups. The location of the lesion, time interval between the onset of stroke and transfer to rehabilitation, neurologic deficits, discharge destination, and gender were comparable among the groups.

Patients with ischemic strokes from all age groups with or without hypertension are included. Patients had to complete their inpatient rehabilitation without interruption of their rehabilitation stay. Patients with hemorrhagic strokes and those with previous strokes and whose rehabilitation was interrupted from any medical complications were excluded. Patients' functional performance was assessed on the Functional Independence Measure (FIM) on admission, weekly, and at discharge. For each group the averages of the length of stay (LOS), FIM score, and the efficiency ratio (ER) were obtained from the records. The ER is the difference of discharge to Admission FIM expressed as a fraction of the Length of Stay. We considered that ER as the main functional outcome measure. Co-morbidity, medical complications and presence or absence of visuo-spatial deficits were also recorded. Demographics of the patients (Table1): there were 272 patients 28 of them were under 49 years, 45 between $50-59$ years, 59 between 60-69 years, 87 between $70-79$ and 43 were over 80 years of age. Comorbidities for the five age groups were depression, diabetes mellitus, coronary artery disease and congestive heart failure (Table1A). There were 142 males comprising of 82 hypertensives and 60 non-hypertensives. Seventy-nine were hypertensive and 51were non-hypertensive of 130 female patients. The admission (ADM) FIM, discharge (D/C) FIM, Length of Stay and Efficiency Ratios were individually tabulated under male, female hypertensive and nonhypertensive groups in (Tables 2A), (Table 2B) and 3a and $3 \mathrm{~b}$. Data for all hypertensives (161) and Non-hypertensives (111) are shown in Tables $4 \mathrm{a}$ and $4 \mathrm{~b}$. The data are also tabulated for all male and all female groups in hypertensive and non- hypertensive categories in Tables 5a and $5 \mathrm{~b}$ and Table 6 show all the 272 patients data. The results are tabulated with their significance in table 7 and their correlation in table 8 .

Table I Demographics $n=272$.

\begin{tabular}{llllll}
\hline Age (years) & $\leq \mathbf{4 9}$ & $\mathbf{5 0 - 5 9}$ & $\mathbf{6 0 - 6 9}$ & $\mathbf{7 0 - 7 9}$ & $\mathbf{2 0}$ \\
\hline (n) & 28 & 45 & 69 & 87 & 43 \\
Male & 12 & 27 & 43 & 39 & 20 \\
Female & 16 & 18 & 26 & 48 & 23 \\
Lt. CVA & 10 & 23 & 33 & 38 & 20 \\
Rt. CVA & 16 & 21 & 35 & 48 & 22 \\
Br. Stem & 2 & 1 & 1 & 1 & 1 \\
Hypertensive & 11 & 26 & 47 & 48 & 31 \\
Non-hypertensive & 17 & 19 & 22 & 39 & 12 \\
\hline
\end{tabular}

Abbreviations CVA, cerebrovascular accident; BR, brain

Table 2A Male hypertensives $n=82$

\begin{tabular}{|c|c|c|c|c|c|}
\hline Age (years) & $\leq 49$ & $50-59$ & $60-69$ & 70-79 & $\geq 80$ \\
\hline (n) & 28 & 45 & 69 & 87 & 43 \\
\hline Depression & 2 & 6 & 4 & 4 & 2 \\
\hline $\begin{array}{l}\text { Coronary Artery } \\
\text { Disease }\end{array}$ & 3 & 9 & 15 & 17 & 6 \\
\hline $\begin{array}{l}\text { Congestive Heart } \\
\text { Failure }\end{array}$ & I & I & 5 & 4 & 3 \\
\hline Diabetes & 5 & 29 & 21 & 24 & 12 \\
\hline
\end{tabular}

Abbreviations A-FIM, admission functional independence measure; D-FIM, discharge functional independence measure; LOS, Length of Stay; ER, efficiency ratio

Table 2B Male non-hypertensives $n=60$

\begin{tabular}{|c|c|c|c|c|c|c|}
\hline \multicolumn{2}{|c|}{ Age (years) } & \multirow{2}{*}{$\begin{array}{l}\leq 49 \\
4\end{array}$} & \multirow{2}{*}{$\begin{array}{l}\text { 50-59 } \\
4\end{array}$} & \multirow{2}{*}{$\begin{array}{l}60-69 \\
31\end{array}$} & \multirow{2}{*}{$\begin{array}{l}70-79 \\
18\end{array}$} & \multirow{2}{*}{$\begin{array}{l}\geq \mathbf{8 0} \\
15\end{array}$} \\
\hline (n) & & & & & & \\
\hline \multirow[t]{2}{*}{ A-FIM } & Avg. & 45 & 47.4 & 40.1 & 45.2 & 39 \\
\hline & St. Dev. & 20.3 & 13.6 & II.I & 14.6 & 8.5 \\
\hline \multirow[t]{2}{*}{ D-FIM } & Avg. & 74.3 & 72.4 & 66.4 & 66.1 & 62.5 \\
\hline & St. Dev. & 5.3 & 5.6 & 11.8 & 12.6 & 16.4 \\
\hline \multirow[t]{2}{*}{ LOS } & Avg. & 32.3 & 25.8 & 30.2 & 24.8 & 30.2 \\
\hline & St. Dev. & 10.3 & 27.7 & 11.6 & II.3 & 10.3 \\
\hline \multirow[t]{2}{*}{ ER } & Avg. & 0.97 & 1.05 & I & 1.04 & 0.93 \\
\hline & St. Dev. & 0.46 & 0.94 & 0.56 & 0.68 & 0.63 \\
\hline
\end{tabular}

Abbreviations A-FIM, admission functional independence measure; D-FIM, discharge functional independence measure; LOS, Length of Stay; ER, efficiency ratio 
Table 3A Female hypertensives $n=79$

\begin{tabular}{lllllll}
\hline \multicolumn{1}{l}{ Age (years) } & $\leq \mathbf{4 9}$ & $\mathbf{5 0 - 5 9}$ & $\mathbf{6 0 - 6 9}$ & $\mathbf{7 0 - 7 9}$ & $\geq \mathbf{8 0}$ \\
\hline (n) & & 7 & 12 & 16 & 28 & 16 \\
A-FIM & Avg. & 48.4 & 38.7 & 49.4 & 42.6 & 50.6 \\
& St. Dev. & 19.1 & 13.6 & 12.7 & 14.9 & 15.1 \\
\multirow{2}{*}{ D-FIM } & Avg. & 70.4 & 64.8 & 71.6 & 64.6 & 70.7 \\
& St. Dev. & 19.5 & 17.6 & 13.1 & 17.9 & 11.1 \\
\multirow{2}{*}{ LOS } & Avg. & 22.7 & 32.7 & 22.4 & 31.6 & 24.3 \\
& St. Dev. & 13 & 15.7 & 9.1 & 13.1 & 9.9 \\
\multirow{2}{*}{ ER } & Avg. & 1.37 & 1 & 1.27 & 0.85 & 0.89 \\
& St. Dev. & 0.84 & 0.64 & 1.1 & 0.54 & 0.39 \\
\hline
\end{tabular}

Abbreviations A-FIM, admission functional independence measure; D-FIM, discharge functional independence measure; LOS, Length of Stay; ER, efficiency ratio

Table 3B Female non-hypertensives $n=5$ I

\begin{tabular}{lllllll}
\hline \multicolumn{1}{l}{ Age (years) } & $\leq \mathbf{4 9}$ & $\mathbf{5 0 - 5 9}$ & $\mathbf{6 0 - 6 9}$ & $\mathbf{7 0 - 7 9}$ & $\geq \mathbf{8 0}$ \\
\hline (n) & & 9 & 6 & 10 & 20 & 6 \\
A-FIM & Avg. & 41.8 & 48.3 & 32.6 & 46.8 & 42.2 \\
& St. Dev. & 15.3 & 19.4 & 11.2 & 16.3 & 11.1 \\
\multirow{2}{*}{ D-FIM } & Avg. & 75.6 & 69 & 57.5 & 67.1 & 63.5 \\
& St. Dev. & 14 & 14 & 15.7 & 14.5 & 15 \\
\multirow{2}{*}{ LOS } & Avg. & 24.8 & 23 & 39 & 26.7 & 23.3 \\
& St. Dev. & 13.8 & 11.5 & 10.9 & 9.4 & 11.6 \\
\multirow{2}{*}{ ER } & Avg. & 1.9 & 1.04 & 0.71 & 0.8 & 1.23 \\
& St. Dev. & 1.25 & 0.81 & 0.41 & 0.45 & 0.88 \\
\hline
\end{tabular}

Abbreviations A-FIM, admission functional independence measure; D-FIM, discharge functional independence measure; LOS, Length of Stay; ER, efficiency ratio

Table 4A All hypertensives $n=161$

\begin{tabular}{lllllll}
\hline $\begin{array}{l}\text { Age } \\
\text { (years) }\end{array}$ & & $\leq \mathbf{4 9}$ & $\mathbf{5 0 - 5 9}$ & $\mathbf{6 0 - 6 9}$ & $\mathbf{7 0 - 7 9}$ & $\geq \mathbf{8 0}$ \\
\hline (n) & & 11 & 26 & 47 & 46 & 31 \\
A-FIM & Avg. & 47.2 & 43.4 & 43.2 & 43.6 & 45 \\
& St. Dev. & 18.6 & 18.2 & 12.4 & 15.9 & 13.5 \\
\multirow{2}{*}{ D-FIM } & Avg. & 71.8 & 68.9 & 68.2 & 65.2 & 66.7 \\
& St. Dev. & 15.5 & 17.6 & 12.4 & 17.2 & 14.3 \\
LOS & Avg. & 26.2 & 30 & 27.5 & 28.7 & 27.1 \\
& St. Dev. & 12.5 & 15.7 & 11.4 & 13.9 & 10.4 \\
& Avg. & 1.22 & 1.03 & 1.09 & 0.92 & 0.91 \\
& St. Dev. & 0.73 & 0.6 & 0.78 & 0.63 & 0.51 \\
\hline
\end{tabular}

Abbreviations A-FIM, admission functional independence measure; D-FIM, discharge functional independence measure; LOS, Length of Stay; ER, efficiency ratio
Table 4B All non-hypertensives $\mathrm{n}=\mathrm{I}$ I

\begin{tabular}{lllllll}
\hline \multicolumn{1}{l}{ Age (years) } & $\leq \mathbf{4 9}$ & $\mathbf{5 0 - 5 9}$ & $\mathbf{6 0 - 6 9}$ & $\mathbf{7 0 - 7 9}$ & $\geq \mathbf{8 0}$ \\
\hline (n) & & 19 & 22 & 41 & 12 & 12 \\
A-FIM & Avg. & 42.9 & 57.1 & 38.3 & 45.5 & 41.5 \\
& St. Dev. & 12.3 & 15.2 & 16.3 & 16.1 & 12.9 \\
\multirow{2}{*}{ D-FIM } & Avg. & 75.7 & 77.1 & 58.6 & 67.3 & 66.6 \\
& St. Dev. & 10.5 & 10.3 & 17.8 & 13.9 & 14.2 \\
\multirow{2}{*}{ LOS } & Avg. & 23.8 & 18.1 & 20.3 & 29.1 & 23.8 \\
& St. Dev. & 11 & 8.5 & 10.9 & 14.4 & 11.3 \\
\multirow{2}{*}{ ER } & Avg. & 1.7 & 1.3 & 0.65 & 0.82 & 1.25 \\
& St. Dev. & 0.95 & 0.9 & 0.43 & 0.5 & 0.68 \\
\hline
\end{tabular}

Abbreviations A-FIM, admission functional independence measure; D-FIM, discharge functional independence measure; LOS, Length of Stay; ER, efficiency ratio

Table 5A Male hypertensives and non-hypertensives together $n=\mid 42$

\begin{tabular}{lllllll}
\hline \multicolumn{1}{l}{ Age (years) } & $\mathbf{4 9 9}$ & $\mathbf{5 0 - 5 9}$ & $\mathbf{6 0 - 6 9}$ & $\mathbf{7 0 - 7 9}$ & $\geq \mathbf{8 0}$ \\
\hline (n) & & 12 & 27 & 43 & 39 & 21 \\
A-FIM & Avg. & 44.4 & 54 & 40.9 & 44.7 & 39.5 \\
& St. Dev. & 12.6 & 18.2 & 13.5 & 15.3 & 10.6 \\
\multirow{2}{*}{ D-FIM } & Avg. & 75.3 & 76.4 & 64.5 & 66.9 & 64.6 \\
& St. Dev. & 5 & 13.6 & 14.6 & 13 & 15.7 \\
\multirow{2}{*}{ LOS } & Avg. & 25.9 & 22 & 30.2 & 28.1 & 28.5 \\
& St. Dev. & 9.3 & 13.7 & 11.5 & 15.4 & 10.9 \\
\multirow{2}{*}{ ER } & Avg. & 1.31 & 1.23 & 0.89 & 0.94 & 1.03 \\
& St. Dev. & 0.47 & 0.78 & 0.56 & 0.61 & 0.6 \\
\hline
\end{tabular}

Abbreviations A-FIM, admission functional independence measure; D-FIM, discharge functional independence measure; LOS, Length of Stay; ER, efficiency ratio

Table 5B Female hypertensives and non-hypertensives together $n=130$

\begin{tabular}{lllllll}
\hline \multicolumn{1}{c}{ Age (years) } & & $\leq 49$ & $\mathbf{5 0 - 5 9}$ & $\mathbf{6 0 - 6 9}$ & $\mathbf{7 0 - 7 9}$ & $\mathbf{2 8 0}$ \\
\hline (n) & & 16 & 18 & 26 & 48 & 22 \\
A-FIM & Avg. & 44.7 & 41.8 & 42.9 & 44.3 & 48.3 \\
& St. Dev. & 16.8 & 15.9 & 14.5 & 16.6 & 14.4 \\
D-FIM & Avg. & 73.3 & 66.2 & 66.2 & 65.7 & 68.7 \\
& St. Dev. & 16.2 & 16.2 & 15.5 & 17.6 & 12.3 \\
LOS & Avg. & 23.9 & 29.4 & 22.4 & 29.5 & 24 \\
& St. Dev. & 13.1 & 14.4 & 8.9 & 12.9 & 10.1 \\
& Avg. & 1.67 & 1.01 & 1.06 & 0.83 & 0.98 \\
& St. Dev. & 1.11 & 0.67 & 0.93 & 0.53 & 0.56
\end{tabular}

Abbreviations A-FIM, admission functional independence measure; D-FIM, discharge functional independence measure; LOS, Length of Stay; ER, efficiency ratio 
Table 6 Hypertensive and non-hypertensive males and females $n=272$

\begin{tabular}{lllllll}
\hline \multicolumn{1}{l}{ Age (years) } & $\leq \mathbf{4 9}$ & $\mathbf{5 0 - 5 9}$ & $\mathbf{6 0 - 6 9}$ & $\mathbf{7 0 - 7 9}$ & $\geq \mathbf{8 0}$ \\
\hline (n) & & 28 & 45 & 69 & 87 & 43 \\
\multirow{2}{*}{ A-FIM } & Avg. & 44.6 & 49.1 & 41.7 & 44.5 & 44 \\
& St. Dev. & 14.9 & 18.1 & 13.8 & 15.9 & 13.3 \\
\multirow{2}{*}{ D-FIM } & Avg. & 74.2 & 72.3 & 65.1 & 66.2 & 66.7 \\
& St. Dev. & 12.6 & 15.4 & 14.9 & 15.6 & 14.1 \\
\multirow{2}{*}{ LOS } & Avg. & 24.8 & 25 & 30 & 28.9 & 26.2 \\
& St. Dev. & 11.4 & 14.3 & 12.2 & 14 & 10.6 \\
\multirow{2}{*}{ ER } & Avg. & 1.51 & 1.14 & 0.95 & 0.88 & 1 \\
& St. Dev. & 0.88 & 0.74 & 0.72 & 0.57 & 0.58 \\
\hline
\end{tabular}

Abbreviations A-FIM, admission functional independence measure; D-FIM, discharge functional independence measure; LOS, Length of Stay; ER, efficiency ratio

Table 7 Analysis of variance (ANOVA). F- ratio and p-values

\begin{tabular}{lllllll}
\hline & Males & & Females & \multicolumn{2}{c}{$\begin{array}{l}\text { Males and } \\
\text { females }\end{array}$} \\
\hline Hypertensive & $\mathrm{n}=82$ & & $\mathrm{n}=79$ & \multicolumn{2}{c}{$\begin{array}{l}\mathrm{n}= \\
\mathrm{I}=\mathrm{I}\end{array}$} \\
& $\mathrm{F}$ & $\mathrm{P}$ & $\mathrm{F}$ & $\mathrm{P}$ & $\mathrm{F}$ & $\mathrm{P}$ \\
A-FIM & $\mathrm{I} .09$ & 0.3 & $\mathrm{I} .58$ & 0.19 & 0.2 & 0.94 \\
D-FIM & $\mathrm{I} .23$ & $0.3 \mathrm{I}$ & 0.72 & 0.58 & 0.57 & 0.69 \\
LOS & 0.89 & 0.48 & 2.35 & 0.06 & 0.3 & 0.88 \\
ER & 0.1 & 0.98 & 1.44 & 0.23 & 0.97 & 0.43
\end{tabular}

\begin{tabular}{lllllll}
$\begin{array}{llllll}\text { Non- } \\
\text { hypertensive }\end{array}$ & $\mathrm{n}=60$ & & $\mathrm{n}=5 \mathrm{I}$ & \multicolumn{3}{c}{$\mathrm{III}$} \\
& $\mathrm{F}$ & $\mathrm{P}$ & $\mathrm{F}$ & $\mathrm{P}$ & $\mathrm{F}$ & $\mathrm{P}$ \\
A-FIM & 2.78 & 0.03 & $\mathrm{I} .69$ & 2.57 & 4.32 & 0.003 \\
D-FIM & 4.45 & 0.003 & $\mathrm{I} .92$ & 0.12 & 5.93 & 0.0002 \\
LOS & 3.96 & 0.006 & 0.42 & 0.79 & 3.52 & 0.01 \\
ER & 4.45 & 0.004 & 4.2 & 0.006 & $8.1 \mathrm{II}$ & 0.00005
\end{tabular}

\begin{tabular}{|c|c|c|c|c|c|c|}
\hline \multicolumn{7}{|c|}{ Hypertensive and } \\
\hline \multirow[t]{2}{*}{$\begin{array}{l}\text { Non- } \\
\text { hypertensive }\end{array}$} & \multicolumn{2}{|l|}{$\begin{array}{l}\mathrm{n}= \\
\mathrm{I} 42\end{array}$} & \multicolumn{2}{|l|}{$\mathrm{n}=130$} & \multicolumn{2}{|l|}{$\begin{array}{l}n= \\
272\end{array}$} \\
\hline & $\mathrm{F}$ & $\mathrm{P}$ & $\mathrm{F}$ & $P$ & $\mathrm{~F}$ & $P$ \\
\hline A-FIM & 4.14 & 0.0034 & 0.51 & 0.73 & 1.63 & 0.17 \\
\hline D-FIM & 4.52 & 0.002 & 0.79 & 0.54 & 3.18 & 0.0141 \\
\hline LOS & 2.04 & 0.09 & 2.44 & 0.05 & 1.74 & 0.14 \\
\hline ER & 2.07 & 0.09 & 3.99 & 0.004 & 5.27 & 0.0004 \\
\hline
\end{tabular}

Abbreviations A-FIM, admission functional independence measure; D-FIM, discharge functional independence measure; LOS, Length of Stay; ER, efficiency ratio
Table 8 Correlation of ( $r$ ) age and ER and Student's $t$

\begin{tabular}{|c|c|c|c|c|c|c|}
\hline \multirow{3}{*}{ Hypertensive } & \multicolumn{2}{|l|}{ Males } & \multicolumn{2}{|l|}{ Females } & \multicolumn{2}{|c|}{$\begin{array}{l}\text { Males and } \\
\text { females }\end{array}$} \\
\hline & $n=82$ & & $n=79$ & & $\mathrm{n}=161$ & \\
\hline & $r$ & $\mathrm{t}$ & $r$ & $\mathrm{t}$ & $r$ & $\mathrm{t}$ \\
\hline \multirow{4}{*}{$\begin{array}{l}\text { Non- } \\
\text { hypertensive }\end{array}$} & -0.08 & -0.74 & -0.19 & -0.17 & -0.15 & -1.91 \\
\hline & $n=60$ & & $n=51$ & & $\mathrm{n}=\mathrm{II} \mid$ & \\
\hline & $r$ & $\mathrm{t}$ & $r$ & $\mathrm{t}$ & $r$ & $\mathrm{t}$ \\
\hline & -0.3 & -2.5 & -0.48 & -3.8 & -0.39 & -4.4 \\
\hline \multirow{3}{*}{$\begin{array}{l}\text { Hypertensive } \\
\text { and Non- } \\
\text { hypertensive }\end{array}$} & $\begin{array}{l}n= \\
142\end{array}$ & & $n=130$ & & $n=272$ & \\
\hline & $r$ & $\mathrm{t}$ & $r$ & $\mathrm{t}$ & $r$ & $\mathrm{t}$ \\
\hline & -0.2 & $-2.4 I$ & -0.33 & -3.94 & -0.27 & -4.6 \\
\hline
\end{tabular}

In this study, the differences among the averages of the five age groups for each of the four functional measures A-FIM, D-FIM, LOS and ER are statistically analyzed. The evaluation is conducted separately for the male-female and hypertensive-non-hypertensive groups. The Analysis of Variance (ANOVA) method, F-ratios and Student's t-tests were employed for the statistical evaluation. The ANOVA is an extension of the Student's t-test employed to examine the hypothesis related to the differences among the means of more than two groups. The effect of age is further examined from its correlation with ER. Correlation significantly different from zero indicates difference of ER among the age groups. Examining this correlation is statistically equivalent to the evaluation of the relation between ER and age through regression analysis.

\section{Results}

The averages and standard deviations of the four functional measures appear in (Tables 2) (Tables 3) (Tables 4) (Tables 5) (Tables 6). The F-ratios and p-values for the ANOVA tests are presented in Table 7. The correlations of age with ER along with the corresponding values of the Student's $t$ are presented in Table 8. The following observations are made from all these tables, from (Tables 7) (Tables 8).

Age: There is a significant difference $(\mathrm{p}<0.0004)$ among the five age groups for the means of ER for the male and female hypertensive and non-hypertensive patients together. The ER for patients below 60 years of age is found to be significantly higher than for patients over 60 years $(\mathrm{p}<0.00001)$. The means of the ER are 1.28 , and 0.93 with the difference of 0.35 and its standard error of 0.105 . Non-hypertensive patients had higher ER compared to the hypertensives for all the age groups (Tables $4 \mathrm{a}$ and $4 \mathrm{~b}$ ). This difference is significant for patients younger than 60 years $(p<0.01)$ and older than 80 years $(p<0.00001)$.

Hypertension: ER for non-hypertensive patients below age 60 is significantly higher $(p<0.05)$ than for the hypertensives. Among the patients over 60 years of age, there is no significant difference for the ER between non-hypertensives and hypertensives, (Tables 2A), (Table 2B) and (Tables 3A), (Table 3B).

The average lengths of stay (LOS) for the five age groups were $25,25,30,29$ and 26 days, respectively. The mean efficiency ratios 
for the groups were $1.51,1.14,0.95,0.88$ and 1.00 respectively (see Table. 6). The difference of the average ER among the five age groups is significant for the non-hypertensive males as well as for females. The hypertensive patients' LOS in general is longer compared to nonhypertensives. The average ER for the age groups 60-69 and 70-79 is less than one but $>1$ for the remaining three age groups. The ADM and D/C FIM scores were lower for the non hypertensives for the 60-69 group to account for the lower ER. For the hypertensive males and females, the differences among the means for the functional measures are not significant. These results may be attributed to either stable hypertension or better management of hypertension during their rehabilitation stay.

The results can be further elaborated as follows:

1. For the male non-hypertensives, the difference among the means is significant for each of the four functional measures; $p<0.03$ for A-FIM and $<0.006$ for the remaining three measures.

2. For the female non- hypertensives, the difference among the means of the age groups is significant only for the ER $(p<0.006)$, but not for the remaining three measures (Tables 7).

3. For the 60-79 year- old (male and female) non-hypertensives, the LOS is longer relative to the remaining four age groups. For the (60-69 age group) male non-hypertensives, the FIM gain is smaller relative to the remaining four age groups. These are the two reasons for the significant differences in (a) and (b) for the ERs of both males and females (Table 2B).

4. For the male as well as female non-hypertensives in the age groups (60-69) and (70-79), the LOS is longer relative to the other three groups (Table 2B) \& (Table 3B), resulting in the ER $<1$ compared to $>1$ for the other age groups.

5. For both the male and female hypertensives, the differences among the age groups are not significant for the four functional measures, especially the ER. It is only slightly significant for the LOS of the female hypertensives $(\mathrm{p}<0.06)$ (Tables 7).

6. The correlations of ER with age are negative for the male-female as well as the hypertensive-no hypertensive groups (see Table 8), that is, ER decreases with age for all these categories. Further, the decrease of ER with age is significant for the non-hypertensive males as well as females. Similar results can be expected from the regression of ER on age.

\section{Discussion}

Effect of hypertension and its impact on an individual's outcome measured in FIM scale has not been studied previously. Our study examined the presence or absence of hypertension and its impact retrospectively and found that presence of hypertension itself had a clear impact on the functional outcome as measured by ER. It is significantly higher for the non-hypertensive patients in the younger age groups $(n=41)$ vs 37 patients under 60 years of age $(2.70$ vs 1.22). Hypertension did not affect functional progress of stroke patients $(n=93)$ between 60-79 years of age The possible explanation is that older individuals are more likely to have pre-existing disease and disabilities which may have effects on their functional recovery. It is possible that other factors such as co-morbidities may have had a stronger impact on functional recovery in older age groups, and thus presence or absence of hypertension did not make a significant difference in those groups. There is no consensus on the influence of age on the outcome of rehabilitation after stroke. Most studies in the literature showed negative outcomes with increasing age. A few studies pointed out the absence of the effect of age on the outcomes. Earlier studies reflected utilizing the Barthel index to measure functional progress of patients in rehabilitation settings. Our study showed that patients younger than 60 years of age with no history of hypertension had better progress in rehabilitation. This group of 73 patients with no hypertension showed better functional performance on FIM scores and ER. Also the oldest group of 31 patients $>80$ years have shown better functional outcomes in this study. The FIM is a widely accepted functional outcome measure, currently used in the rehabilitation units across the US. In a Meta-analysis of 11 studies by Ottenbacher and Granger, ${ }^{23}$ the FIM instrument demonstrated acceptable reliability across a wide variety of settings, raters, and patients. The study by Bagg et al. ${ }^{17}$ found that advanced age had no effect on the FIM scores. In their sample of 561 patients age is reported to be a significant prognostic factor for acute and long-term mortality and functional recovery. The study by Adler (7) suggested that compared to younger patients, older individuals may have more severe deficits from strokes and hence do less well. As age advances, cognitive skills may also decline. In our study, we had excluded patients with dementia or cognitive deficits.

It was also postulated by some researchers that older brains may intrinsically have less ability to recover, although the elderly may be more likely to employ compensatory strategies to overcome some of the neural impairment that remains after stroke. More studies are required to show that age itself is not a factor in determining the outcome after stroke. Research also needs to focus on patients older than 79 years.

The clinical impact of this study is enormous when the stroke statistics are taken into consideration. Every year about 140,000 Americans die from stroke. In 2016, stroke accounted for about one out of every 19 deaths in the US. Every 40 seconds, someone in the United States has a stroke and there is a death every 4 minutes from stroke. ${ }^{24}$ Stroke risk varies by age. In $2009,34 \%$ of people hospitalized for stroke were less than 65 years old. ${ }^{25}$ Stroke reduces mobility in more than half of stroke survivors age 65 and over. ${ }^{26}$ Memis and colleagues ${ }^{27}$ found in their study that age had no effect on functional status and disability of stroke patients.

Feigin et $\mathrm{al}^{28}$ described the global impact of stroke and its consequences emphasizing the need for more efficient prevention strategies. Hypertension being the major contributor for the disease, our study evaluated its impact especially on functional outcomes.

The limitations of the study are that it is a retrospective analysis and we were unable to find how many of the hypertensives had swings or variability of their blood pressures and whether they were symptomatic from it during rehabilitation. Patients' admission blood pressures and their effect on the participation in therapies were not reported. The collection of the FIM scores to assess maintenance of the functional gains at 3 months and at one year would have been helpful to determine the influence of age and hypertension in this population. Future studies are needed to study the impact of the variations in blood pressure of stroke patients during rehabilitation and their functional gains.

\section{Conclusion}

Stroke Patients younger than 60 years of age with no hypertension showed better progress with inpatient rehabilitation as measured on 
the Functional Independent Measure in our retrospective study of 272 subjects. .

\section{Acknowledgements}

None

\section{Conflict of interest}

The authors declare no conflicts of interest.

\section{References}

1. World health organization: world health report. Internet; 2007.

2. Samsa GP, Matchar DB, Goldstein L, et al. Utilities for major stroke. Results from a survey of preferences among persons at increased risk for stroke. Am Heart J. 1998;136(4 part 1):703-713.

3. Rosamond W, Flegal K, Furie K, Go A, et al. Heart disease and stroke statistics -2008 update: a report from the american heart association statistics committee and stroke statistics subcommittee. Circulation. 2008;29:117:e25-146.

4. Rankin, J. Cerebral vascular accidents in patients over the age of 60. II. Prognosis. Scott Med J. 1957;2(5):200-215.

5. Cain LS. Determining the factors that affect rehabilitation. J Am Geriatrics Soc. 1969;17:595.

6. Lehmann JF, DeLateur BJ, Fowler RS. et al. Stroke Rehabilitation: outcome and prediction. Arch Phy Med Rehabil. 1975;56, 383-389.

7. Adler, MK, Brown CC, Acton P. Stroke rehabilitation--is age a determinant?. J Am Geriatr Soc. 1980;28(11):499-503.

8. Gresham GE. Rehabilitation of the geriatric patient. Stroke rehabilitation, the rehabilitation team, and the usefulness of functional assessment. Prim Care. 1982;9(1):239-247.

9. Wade DT, Langton HR, Victorine AW. Stroke: the influence of age upon outcome. Age Ageing 1984;13(6):357-362.

10. Ferrucci L, Bandinelli S, Guralnik JM, et al. Recovery of functional status after stroke. A post rehabilitation follow-up study. Stroke. 1993 24(2):200-205.

11. Nakayama H, Jørgensen HS, Raaschou HO, et al. The influence of age on stroke outcome. The copenhagen stroke study. Stroke. 1994;25(4):808813.

12. Falconer JA, Naughton BJ, Strasser DC, et al. Stroke inpatient rehabilitation: a comparison across age groups. J Am Geriatr Soc. 1994;42(1):39-44.

13. Kalra L. Does age affect benefits of stroke unit rehabilitation?. Stroke. 1994;25(2):346-351.
14. Kaste M, Palomaki H, Sarna S. Where and how should elderly stroke patients be treated? A randomized trial. Stroke.1995;26(2): 249-253.

15. Black SRM, Winston C.. Age and functional outcome after stroke. Top Stroke Rehabil. 2004; 11(2):23-32.

16. Luk JK, Cheung RT, et al. Does age predict outcome in stroke rehabilitation? A study of 878 Chinese subjects. Cerebrovasc Dis. 2006;1(4):229-234.

17. Bagg S, Pombo AP, Wilma P. Effects of age on functional outcomes after stroke rehabilitation. Stroke. 2002;33(1):179-185.

18. Nazzal ME, Saadah MA, Trebinjac SM, et al. Effect of risk factors on functional outcome after stroke rehabilitation. Neurosciences. 2006;11(1):15-20.

19. Ripley DL, Seel RT, Macciocchi SN, et al. The impact of diabetes mellitus on stroke acute rehabilitation outcomes. Am J Phys Med Rehabil. 2007;86(9):754-761.

20. Salehi S, Tahan N, Bagheban AA, et al. Quality of life within three months after stroke: a study in the city of arak, Iran. J Natl Med Assoc. 2019;S00279684(19):30043-30044.

21. Cao Q, Zhou S, Cai B, et al. The impacts of premorbid hypertension treatment on functional outcomes of ischemic stroke. J Neurol Sci. 2016;15(363):1-4.

22. Tanovic E, Selimovic S, Tanovic H. Assessment of the effects of rehabilitation after cerebrovascular accident in patients with diabetes mellitus and hypertension as risk factors. Med Arch. 2014;68(2):12.

23. Ottenbacher KJ, Hsu Y, Granger CV, et al. The reliability of the functional independence measure: a quantitative review. Arch Phys Med Rehabil. 1996;77(12):1226-1232.

24. Vital Signs: Recent trends in stroke death rates-United States, 2000-2015. MMWR; 2017:66.

25. Hall MJ, Levant S, DeFrances CJ. Hospitalization for stroke in U.S hospitals, 1989-2009. National center for health statistics. 2012;(95):1-8.

26. Benjamin EJ, Blaha MJ, Chiuve SE, et al. on behalf of the American Heart Association Statistics Committee and stroke statistics subcommittee. heart disease and stroke statistics-2017 update: a report from the American Heart Association. Circulation. 2017;135:e229--e445.

27. Memis D, Kozanoglu E, Kelle B, et al. Assessment of demographic and clinical characteristics on functional status and disability of patients with stroke. Neurosciences. 2016;21(4):352-357.

28. Feigin VL, Krishnamurthi RV, Parmar P, et al. Update on the global burden of ischemic and hemorrhagic stroke in 1990-2013: The GBD 2013 study. Neuroepidemiology. 2015;45(3):161-176. 